\title{
El radiólogo ante la donación de órganos
}

\section{The radiologist and the organ donation}

Katiuzka Casares-Cruz*

Departamento de Neuroimagen, Instituto Nacional de Neurología y Neurocirugía, Ciudad de México, México

El papel del médico radiólogo se hace cada vez más importante para la toma de decisiones en el ámbito legal, tanto en la práctica privada como en la hospitalaria.

Su área de injerencia actualmente incluye su participación en el equipo de trasplante de órganos, en el que es la pieza clave para iniciar el proceso de donación.

La cultura de la donación de órganos ha hecho posible incrementar el tiempo de vida de la población a nivel mundial, y México es uno de los países en los que esta práctica va en incremento gracias a los esfuerzos de las diferentes entidades encargadas de su promoción y de la concientización de la población.

De acuerdo con el artículo 331 de la Ley General de Salud en México, la obtención de órganos o tejidos para trasplantes se hará preferentemente de sujetos en los que se haya comprobado la pérdida de la vida ${ }^{1}$, que, de acuerdo con los artículos 343 y 344, ocurre cuando se presentan datos clínicos de muerte encefálica o paro cardíaco irreversible.

Para hablar de muerte cerebral es importante tener en cuenta el contexto legal, que la considera cuando existe pérdida permanente e irreversible de las funciones cerebrales corroborado ya sea por un electroencefalograma que demuestre ausencia total de actividad eléctrica, o por algún estudio de gabinete que demuestre en forma documental la ausencia permanente de flujo encefálico arterial ${ }^{1}$, tales como eco-Doppler transcraneal, angiografía con sustracción digital, angiorresonancia, angiotomografía y/o tomografía computarizada por emisión de fotón único (SPECT). Aquí es donde entra el médico radiólogo como la parte más importante del proceso de donación, ya que sin un reporte que indique la ausencia de flujo cerebral no es posible continuar con el proceso. Sin embargo, dar un diagnóstico de muerte cerebral siempre es difícil, lo que 
hace que el médico radiólogo dude ante esta responsabilidad.

Dentro de los estudios utilizados sobresale la angiotomografía, debido a su disponibilidad las $24 \mathrm{~h}$ los 7 días de la semana y a que las imágenes permiten una valoración objetiva capaz de ser corroborada por otro médico.

Una vez realizado el diagnóstico de muerte cerebral se inician las fases del proceso de obtención de órganos.

Para ser donador de órganos, hasta hace unos años era necesario contar con una tarjeta con nombre y firma, donde se autorizaba la donación, sin embargo, eso cambió, y actualmente la Ley General de Salud, en su capítulo IV, menciona que la decisión es familiar y consentida. Incluso ahora se puede uno registrar como donador vía internet en la página https://www.gob.mx/cenatra

Para ser receptor es importante estar en un centro hospitalario en donde se realice protocolo de trasplante orgánico o de tejidos, así como estar dado de alta en la lista de espera del CENATRA (Centro Nacional de Trasplantes), al menos $48 \mathrm{~h}$ antes de la recepción.

Son varios los órganos que se pueden trasplantar de un solo donante, pero los más frecuentes según el CENATRA son: corazón, válvulas cardíacas, riñones, hígado, páncreas y pulmones, así como tejidos como lo son las córneas, la piel y los huesos.

En México, la donación de órganos inició en 1999 y las cifras han ido en incremento en un $1,000 \%$ desde el inicio en el primer año hasta el 2018.
Actualmente se realizan aproximadamente 638 trasplantes al año, de los cuales los de riñón son los que ocupan el primer lugar, con 590 pacientes, seguidos por los trasplantes de hígado, con 223 pacientes, y de corazón, con 26 pacientes trasplantados.

En México, las cifras arrojadas hasta 2018 en lista de trasplante son: 15,072 pacientes en espera de riñón, 6,445 pacientes en espera de córneas, 35 pacientes en espera de hígado, 34 pacientes en espera de corazón, 4 pacientes en espera de riñón-páncreas, 3 pacientes en espera de pulmón, y 2 pacientes en espera de hígado-riñón².

Las cifras de trasplante van en incremento, por lo que se necesitan más hospitales generadores, con la capacitación e infraestructura para mantener el soporte vital de los donadores, y más hospitales receptores, con la infraestructura y personal con capacitación y experiencia en trasplantes y seguimiento de la evolución de los pacientes.

Hasta diciembre de 2018, en México se encuentran con registro vigente para trasplante de órganos 538 hospitales $^{2}$. Sin embargo, aún con este importante crecimiento en el área de trasplantes, existe un acentuado desequilibrio entre el número de órganos disponibles y el de potenciales receptores, ya que a nivel mundial solo se satisface el $10 \%$ de la necesidad de trasplante orgánico ${ }^{3,4}$.

En la ciudad de México, se encuentran el 70\% de los hospitales que participan en la generación de esperanza de vida a través del trasplante, y de estos, los que participan más activamente son el Instituto Nacional de Ciencias Médicas Salvador Zubirán, el Hospital 
General Dr. Manuel Gea González, el Hospital General de México y el Hospital Infantil de México Federico Gómez.

Uno de los hospitales en la ciudad de México que es donador de vida es el Instituto Nacional de Neurología y Neurocirugía Manuel Velasco Suárez, que en el 2018 tuvo cifras históricas, con 19 donantes orgánicos, y estuvo dentro de los primeros 5 lugares a nivel nacional en generación orgánica ${ }^{5}$.

Como hemos podido ver, la cultura de la donación ha ido en incremento, y lo que queremos hacer a través de esta editorial de la Revista Anales de Radiología es involucrar a los médicos radiólogos a participar activamente en esta labor humanitaria, comunicándonos con los médicos clínicos y sin tener miedo de realizar el diagnóstico de ausencia de circulación arterial intracraneal, aun cuando esto signifique decir que un paciente no tiene forma de recuperarse.

Con todo lo que esto conlleva, lo primordial para el radiólogo es realizar un diagnóstico correcto ante la ausencia de flujo arterial intracraneal, comunicarle al clínico los hallazgos y entregar el resultado lo más pronto posible, porque en este caso el tiempo es vida para el órgano que está a punto de cambiar de dueño, a punto de salvar una vida, o a mejorar la calidad de vida de un ser humano.
Recordemos que el tiempo pasa incluso para nosotros, nada en esta vida es seguro, y siempre debemos ejercer la medicina pensando que en algún momento, en el futuro, podemos ser nosotros o algún familiar los que estemos en la cama de urgencias, o en un hospital esperando por un órgano para poder continuar con nuestra existencia funcional.

Tengamos siempre eso en mente cuando a las 3 de la mañana nos pidan valorar una angiotomografía por posible donador, no esperemos para dar un resultado, sabemos que no todos los diagnósticos son urgentes, pero este es uno por los que vale la pena desvelarse, y siempre habrá alguien que se lo agradecerá.

\section{CONFLICTO DE INTERESES}

El autor declara que no existe conflicto de intereses.

\section{BIBLIOGRAFÍA}

1. Ley general de salud en México.

2. Boletín anual de donación y trasplantes en México. CENATRA; 2018.

3. Organ donation in adults: a critical care Perspective. Intensive Care Med. 2016;42:305-31.

4. Lesieur O, Leloup M, Gonzalez F, Mamzer MF. Eligibility for organ donation following end-of-life decisions: a study performed in 43, French intensive care units. Intensive Care Med. 2014;40(9):1323-31.

5. Boletín semestral de donación y trasplantes en México. CENATRA. 2018. 